\title{
DECENTRALIZATION AND REGIONAL INFLATION IN INDONESIA
}

\author{
Darius Tirtosuharto \\ Handri Adiwilaga ${ }^{1}$
}

\begin{abstract}
The link between decentralization and inflation as one of the key aspects of macroeconomic stability has been surveyed by a number of studies and the findings are generally inconclusive. Using sample data of developing and developed countries, previous study found that decentralization correlates with lower inflation in developed countries and vice versa, it correlates with higher inflation in developing countries. The key question is what factors play a role in controlling inflation in a decentralized system. This paper is to argue that the coordination problem is the main issue in controlling inflation in a decentralized system, particularly in developing countries. The empirical analysis is to determine the effect of decentralization on regional inflation in Indonesia and whether institutions play a role in the recent downward trend of inflation in Indonesia. A panel data that includes 33 observations of the Indonesian regions (provinces) is constructed with a dummy variable representing the existence of institution. In addition, this study analyzes whether decentralization supports the convergence in regional inflation and also the pattern of spatial correlation in regional inflation. The assumption is that there are some degrees of collective institutional coordination and cooperation with the establishment of Regional Inflation Task Force (RITF).
\end{abstract}

Keywords : Decentralization, Regional Inflation Convergence, Regional Institution

JEL Classification: E31, H73, R12

1 Darius Tirtosuharto (dtirtosuharto@bi.go.id) and Handri Adiwilaga (adiwilaga@bi.go.id) are economist at the Division of Regional Economic Assessment, Department of Economic and Monetary Policy, Bank Indonesia. The views expressed in this paper are solely of the author's and do not necessarily represent the views of Bank Indonesia. 


\section{INTRODUCTION}

The link between decentralization and inflation as one of the key aspects of macroeconomic stability has been surveyed by a number of studies and the findings are generally inconclusive. When the sample analysis is federal and unitary states, the studies could not find a clear relationship between decentralization and the level of inflation. Hence, using sample data of developing and developed countries, the study found that decentralization correlates with lower inflation in developed countries (King \& Ma 2001) and vice versa, it correlates with higher inflation in developing countries (Feltenstein and Iwata 2002). In another study using a large panel data set from several countries, revenue decentralization rather than expenditure decentralization is determined to have a negative association with inflation (Neyapti 2003). The study also found that the size of a country and quality of governance do matter in influencing the impact of fiscal decentralization on inflation.

A number of literatures also focus on certain institutional arrangements that influence the dynamics of price stability in the regions. ${ }^{2}$ This is related to the degree of commitment and coordination in the policy making process. Specifically on commitment, the ability of the authorities to renege on promises for stable prices (stable monetary policies) since inflation can have a positive real effect is an issue (Barro and Gordon 1983). Decentralization is seen as a means to restrain the ability of authorities to renege on sound monetary policies because the control over spending is shared between the central and local governments. On the other hand, there are also cases where decentralization results in higher public spending and borrowing, which puts price stability at risk (Campbell et al. 1991). This commitment problem of decentralization is particularly the case in the federal and unitary system of government.

In the case of a unitary system of government with some levels of decentralization where monetary policy is still a central domain, the more relevant issue is coordination. Policy coordination is a problem affecting macroeconomic stability in which central and local governments are held responsible. In the literature, the coordination problem surfaces when policy makers need to agree on policies for macroeconomic stabilization, yet, there are problems with collective action and asymmetric information (Alesina and Drazen 1991). Decentralization can make coordination a challenge and make it more difficult to control inflation due to uncoordinated actions or policies and also incomplete information that are crucial in the policy decision making process.

This paper argues that the coordination problem is the main issue in controlling inflation in a decentralized system, particularly in developing countries. This is true when inflation is not only a monetary phenomenon of excess demand in which policies can be coordinated by the central authority (central bank), but also a problem on the supply side. Inflation that arises

2 Some of those studies underline the role of the central bank as the authority of monetary stability and government as the authority of fiscal sustainability. The relationship between those two authorities is what creates macroeconomic stability and with decentralization, the balance of fiscal sustainability and responsibility for macro stability is shared between central and local governments. 
mostly due to foods price volatility or supply shock is common in developing countries where dependency on import of foods is high and domestic food production could not keep pace with population growth rate. The problem with food availability and affordability in many developing countries is also driven by problems in infrastructure, logistics and distribution chains.

A number of policies and programs that aim to ease inflation in the short term or overcome the fundamental factors of inflation in developing countries are ineffective and uncoordinated since in many cases; policies are overlapped between government institutions at the central and local levels. Hence, one of the strengths of a decentralized system is the ability of local governments to identify the needs of their regions. Using this logic, then there is optimism that inflation can be monitored and more controllable in a decentralized system. Local governments have more knowledge and information on the sources and factors of inflation in their respective regions. Furthermore, local governments also have the authority to allocate fiscal resources and coordinate other resources including local policies or regulation to support stable and low level of inflation. Price stability is part of the local government task in Indonesia as an effort to improve public welfare.

For that particular reason, where decentralization may support local governments to identify the factors of inflation and use policies to overcome the problems related to inflation in their respective regions, then it is expected that there would a process of convergence. Moreover, local governments in high inflation regions are expected to make an effort to catch up, by better monitoring and controlling inflation in their respective regions.

In the era of decentralization, efforts to manage regional inflation in Indonesia have been supported by institutionalized coordination between Bank Indonesia, central and local governments. The Regional Inflation Task Force (RITF) was initiated as an inter-agency team whose main task is to closely monitor regional inflation and formulate necessary policies to manage regional inflation. RITF has members from various departments within the local government as well as Bank Indonesia in the regional office.

This paper is to determine the effect of decentralization on regional inflation in Indonesia and whether institutions play a role in the recent downward trend of inflation in Indonesia. A panel data that includes 33 observations of the Indonesian regions (provinces) is constructed with a dummy variable representing the existence of RITF institutions in the full scale model. In addition, this study also analyzes the degree of spatial correlation in regional inflation and examines if there is a spatial pattern of collective institutional arrangements in the decentralized system.

The next section discusses the theoretical background of inflation convergence and spatial correlation. Section three discusses the data and estimation method, while result and analysis will be provided in section four. The last section provides conclusion and close the presentation. 


\section{THEORY}

\subsection{Inflation Convergence}

Most studies on convergence of inflation rates have been derived from the experience of the European Union (EU) where inflation convergence has been a major issue following the implementation of the single currency. ${ }^{3}$ In general, the evidence of inflation convergence in the EU area has not been conclusive. There was evidence of convergence of inflation rates after the implementation of a single currency and common monetary policies in the EU area (Beck and Weber 2001, Holmes 2002). Beck and Weber (2001) in particular utilized beta and sigma convergence analysis to examine regional inflation for US, Japan and Europe over the 1981-2001 period. However, there was also an indication of divergence in inflation rates after the start of the single currency policy in the EU (Honohan and Lane 2003, Busetti et al. 2006). Furthermore, Busetti et al. (2006) found that the rate of divergence was different between the cluster of low inflation and high inflation countries.

In the Asian countries, studies on inflation convergence of five ASEAN countries (Indonesia, Thailand, Malaysia, Philippine, Singapore) plus the big three in Asia: China, Japan, and Korea. The finding is that during the pre-crisis period, there was inflation convergence among all countries observed relative to the U.S., except for China and Korea. While in the post-crisis period, the study finds convergence of inflation rates in all countries.

Studies on regional inflation convergence within a country are relatively scarce. From a few studies of inflation convergence in Turkey, there was indication of convergence in the regional inflation rate where common national (centralized) monetary policies were in effect. With a great deal of heterogeneities in regional economies within a country, it is important to evaluate the persistent differences of regional inflation, particularly when it may lead to disparities in regional real interest rates and becomes a concern by the monetary authority.

Recent literature has attempted to examine if inflation-targeting has an impact on inflation convergence. Inflation-targeting is considered effective in reducing both the rate of inflation and inflation expectations. It solves the problem of inflation consistency that typically produces high inflation and to a certain degree can also reduce the impact of a macroeconomic shock. The hypothesis is that countries which have adopted inflation targeting will experience larger falls in their inflation rate. The study by Ball and Sheridan (2004) confirmed this by showing evidence that OECD countries which adopted inflation-targeting have experienced a larger degree of disinflation, compared to other OECD countries.

One of the methods in convergence analysis is the Sigma $(\Sigma)$ and Beta $(\beta)$ convergence test. In examining the convergence of regional inflation, this method is used to test if the inflation

3 The objective of the European Central Bank's (ECB) is to maintain price stability and inflation rates below $2 \%$ in the medium run. In the absence of instruments to fine-tune monetary policy by the ECB, monetary policy in the EU area is to consider the size, persistence and determinants of differences in inflation rates (ECB, 2003). 
gap between regions is narrower. The hypothetical assumption is that local governments would make more effort to control inflation by implementing fiscal and other policy measures as low inflation would raise welfare of the people in their respective regions. Thus, it is expected that regional inflation will converge into a steady state.

Beta $(\beta)$ convergence estimates the growth of regional inflation rate of a certain period of time on its initial level (base year). The $\beta$ convergence test can be expressed in the following equation:

$$
\begin{array}{ll}
\log \left(\pi_{i t}, \pi_{i, t-1)}=a+\beta \log \left(\pi_{i, t-1}\right)+u_{i t}\right. \\
\pi_{i t}: \text { inflation rate in region } i(1, \ldots N) \text { at time } t, \\
\pi_{i, t-1}: \text { inflation rate in region } i(1, \ldots N) \text { at time } t-1, \\
a \quad: \text { initial regional inflation rate } \\
\beta \quad: \text { rate of convergence }
\end{array}
$$

\subsection{Spatial Correlation}

Spatial autocorrelation evaluates both feature locations and attribute values among observations simultaneously (Cliff and Ord 1973). Given a set of features and an associated attribute, spatial auto correlation measures and analyzes the degree of dependency in a geographic setting. The pattern of spatial dependency is categorized as clustered, dispersed, or random in which several statistical methods are utilized to measure the degree of spatial autocorrelation. This study uses Moran's I (index) in which the index value is set between -1.0 and +1.0 . The Moran's index value towards +1.0 indicates clustering, while an index value towards -1.0 indicates dispersion. Along with that, a $Z$ score provides an indication of the significance of the index value.

Testing for spatial autocorrelation of regional inflation has not been widely utilized, as far as the author knows. As a general consensus, the concept of inflation is a monetary phenomenon and commonly disregards the influence of spatial correlation. However, in an environment where supply side factor is a determinant of inflation and influenced by local institutions, examining spatial correlation becomes relevant. Moreover, in a decentralized system of governance, many of the supply side factors of inflation are influenced by local government policies and program initiatives. Those local government policies are either directly or indirectly targeting inflation (price stabilization) through fiscal instruments or budgeted programs.

Among the few, Zsibók and Varga (2009) analyze spatial interdependencies of regional inflation in the European Union (EU), and examine the rate of convergence between countries within this region. The found inflation persistence as main issue, where there was a tendency that inflation between regions in the EU converged slowly towards the target level set by the ECB. Hence, the same aspect is relevant for regions within a single country. 


\section{METHODOLOGY}

The method applied follows the stage of empirical analysis on the dynamics of regional inflation in the era of decentralization in Indonesia. The first stage is to find the nature of the relationship between decentralization and regional inflation and whether there is an indication that inflation between different regions converge. The hypothesis is that local government institutions have an incentive to control inflation in order to improve the welfare of people in their respective regions. In addition, local governments are assumed to know the issues associated with inflation in their respective regions, both from the demand and supply side. Thus, decentralization should correlate with lower inflation and potentially cause regional inflation to convergence, despites various exogenous factors in play, such as a the global foods crisis that affects the imported supply of food commodities

In the following stage, the analysis will test the degree of spatial correlation in regional inflation. We will also observe the spatial autocorrelation in possible existence of collective institutional coordination and cooperation in controlling inflation. It is assumed that neighboring local governments collaborate to control inflation through activities such as cooperating to ensure the availability and adequacy of goods by establishing a logistical center. The importance of collaboration between local governments is also the main goal of establishing RITF. This study is to determine the role of RITF as an institution that focuses on coordination and collaboration to control regional inflation in Indonesia.

In order to determine the correlation between decentralization and regional inflation, this paper constructed two indicators that are a proxy for decentralization. The first one is the fiscal decentralization ratio, which is a ratio of regional (provincial) spending over total national spending. The second indicator is the index of local government performance. The index of local government performance is essentially an efficiency score of local government's expenditure, calculated using Data Envelopment Analysis (DEA) method. ${ }^{4}$

The panel data includes 26 regions (provinces) with the year of observation from 2003 2008. Due to data limitations, observation from year 2001 and 2002 cannot be included. The

4 Data Envelopment Analysis (DEA) is a non-parametric method to measure the relative performance of several Decision Making Units (DMUs in this exercise are the local government entities). The performance of DMUs is measured in terms of relative efficiency when it references a set of units that are being compared to each other. Efficiency of a DMU is computed as the ratio of output produced to input consumed with certain weights ( $\Sigma$ weighted outputs $/ \Sigma$ weighted inputs). The DEA model allows each DMU to maximize the weight multipliers. The weights of inputs and outputs for each DMU vary until the model reaches the best possible combination. The model constructs an efficient production frontier from those observed inputs and outputs. The resulting efficiency index is relative to the DMU's sample observed and the set of weights have to be accounted for other units of assessment in which none of them have an efficiency score greater than one.

Based on the literatures, the performance of government institutions is mainly driven by the analysis of spending or expenditure efficiency (Herrera and Pang, 2005 as followed in the study on fiscal decentralization and state allocative efficiency by Tirtosuharto, 2010). Efficiency index in this study is calculated in the DEA model with capital expenditure and current expenditure as the input variables, while Gross Regional Domestic Product (GRDP) and investments as the outputs. The Granger causality test confirms the direction causality effects from the local governments spending to the GRDP and investments. The efficiency index (score) is included in the exhibit and for a more detail theory and methodology on constructing the efficiency index adopted in this paper, the reference is the study on fiscal decentralization and state allocative efficiency by Tirtosuharto (2010). 
timeframe for the observation in this study represents a period before RITF was formed and therefore, the finding is expected to validate the factual dynamics between decentralization and regional inflation.

A correlation test between fiscal decentralization ratio and regional inflation rate does not provide evidence of strong correlation. However, the sign of the correlation itself is positive, which indicates that a higher degree of fiscal decentralization ratio correlates with higher regional inflation rate. This also implies that by giving more power to govern to the local governments and an authority to use all means and resources in their respective regions may not actually have a positive impact in controlling inflation in the regions. Based on the literature, a larger contribution of government spending (a higher degree of fiscal decentralization) could potentially cause higher inflation, particularly when the spending is directed toward unproductive programs or activities. In addition to wasteful spending, rising debt, corruption and rent-seeking may also increase inflation since it potentially boosts the growth rate of money supply. Public sector corruption and graft in Indonesia's regions after decentralization is believed to be the contributor of inefficient allocation of resources including the capital budget for infrastructure development. These explain the finding of positive correlation between fiscal decentralization and regional inflation.

The institutional measure of decentralization in this study is the index of local government performance. This index is associated with the degree of efficiency in the utilization of public expenditure. The assumption is that the more efficient local governments are in allocating their expenditure that reduces the amount of wasteful spending, there is a probability that inflation rate will be lower. With power over budget and policy making, the quality of local governments is assumed to play a crucial role in controlling inflation through programs that can solve the supply side problems. The sign of correlation between the index of local government performance and regional inflation rate is negative, which implies that efficiency of local governments in utilizing public expenditures could lower the regional inflation rate as expected.

\section{RESULT AND ANALYSIS}

\subsection{Regional Inflation in Indonesia}

Recalling Indonesia's geographic characteristic as a vast archipelago with regional interdependency on supplies, consequently results in a higher dependency on distribution and transport systems to ensure the adequacy and continuity of supply. Smooth distribution ensured adequacy and continuity of supply in many regions. Improvements in Indonesia's distribution system were a result of the growing transport services ${ }^{5}$. However, inflation disparity among

5 The national shipping fleets, which mostly serve domestic freight, experienced a 7\% growth in 2012 over the previous year. In addition, the number of sea freight license holders also increased. Source: Ministry of Transportation, October 2012. 
regions remains a challenge for the country. Inflation in many regions outside Java tends to be higher than in Java and even more fluctuating.

Between 2001 and 2012, the rate of inflation in Indonesia has shown a declining trend. And in the last five years, headline inflation in Indonesia fell from $6.6 \%$ in 2006 to $4.3 \%$ in 2012 (Figure 1). A significant decline in inflation took place in the food components from $10.7 \%$ in 2006 to $5.7 \%$ in 2012 , while inflation in the non-food components only fell from $3.9 \%$ to $3.2 \%$ for the same period. Hence, food prices in Indonesia were higher and more volatile than neighboring countries as there have been frequent disruptions in food supplies and distribution.

A declining trend in national inflation rate is supported by a downward trend of inflation rate in various regions in Indonesia (Figure 1\&2). Inflation outside of the Java region in particular
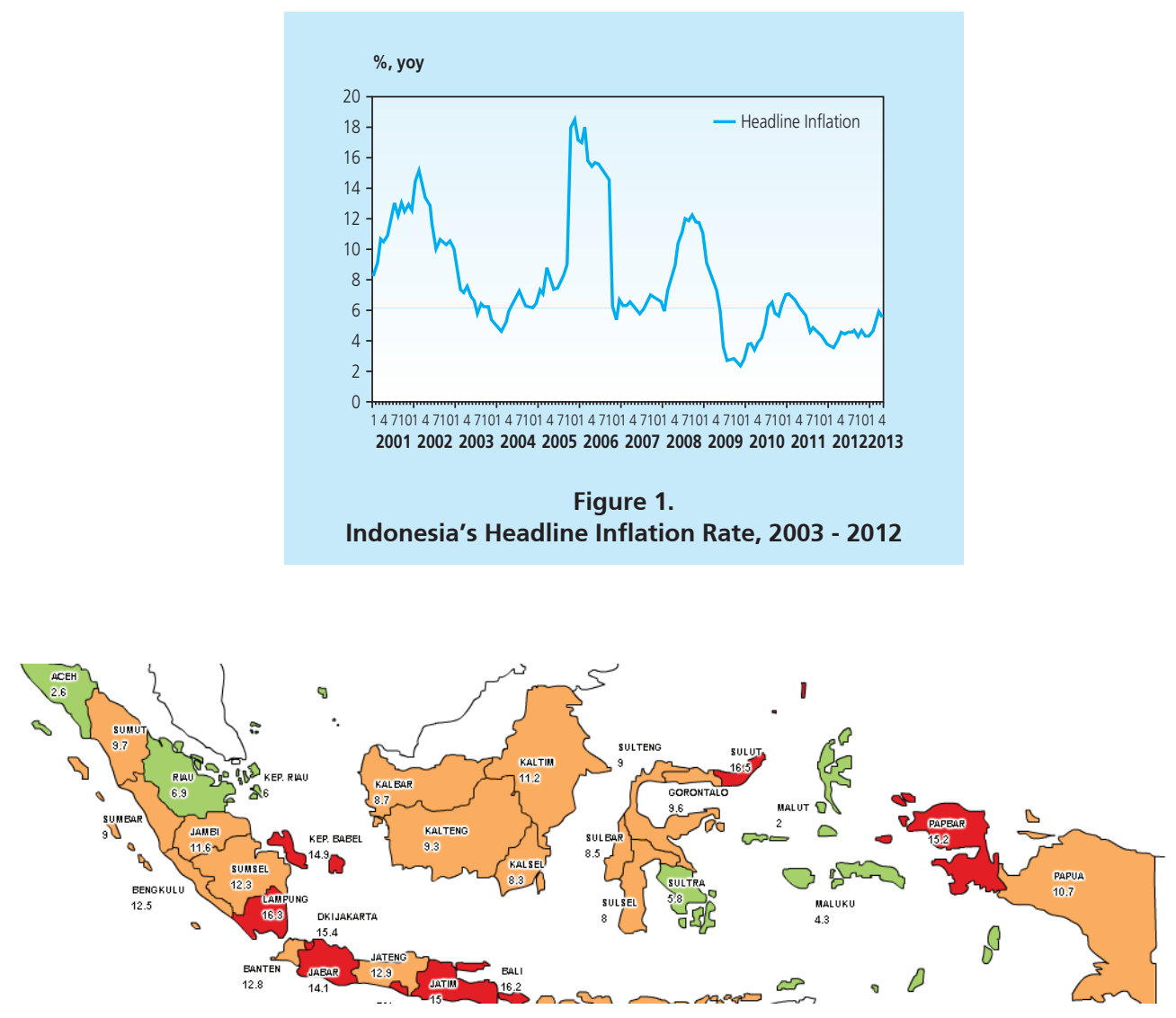

Notes:

areas with food inflation lower than the average national food inflation 2009-2012 (7.78\%)

areas with food inflation higher than the average national food inflation 2009-2012 (7.78\%), but lower than national food inflation on March 2013 (12.95\%)

areas with food inflation higher than national food inflation on March 2013 (12.95\%)

Figure 2. Regional Inflation in 2012 
has dropped substantially over the past couple of years. Inflation in the Sumatera region is even now closer to the national inflation rate. Inflation rate in the Eastern Indonesia region (Kalimantan, Sulawesi, Maluku, and Papua) also showed a downward trend, although its inflation rate is still consistently above the national inflation rate.

The main factors that contribute to a higher inflation rate in the Eastern Indonesian region is the high transportation (distribution) and logistical costs of goods. Meanwhile, inflation rate in Java and Jakarta is historically inline and also nearer to the national inflation rate due to the contribution of inflation from those two regions that stands at $65 \%$. The Java region is also the center of distribution of goods with large scale retail chains that drives competitive prices. Moreover, the infrastructures in these two regions are much improved than other regions and also more integrated. Hence, the demand pressure is higher in the Java region compared to other regions since it is the most populous region and has the fastest rising middle class in the country.

Despite the fact that inflation is a monetary phenomenon where demand-pull factor is dominant, a number of literatures have stressed the supply side factor on regional inflation that mostly took place in developing countries (Hossain 1996, Mohanty \& Klau 2001, Brodjonegoro 2004). This non-monetary factor is driven by the cost-push of goods and services due to the availability, adequacy and affordability of supplies. This supply-side inflation has been an issue in controlling regional inflation in Indonesia in recent years. As part of an initiative to monitor and control inflation in the regions, particularly inflation that is caused by the cost-push factor, RITF was formed as a collaborative effort between central and local governments. This institutional approach to control inflation may not be uncommon in developing countries where coordination and collaboration between local jurisdictions is still an issue.

Looking closer at the co-movement of inflation rates among provinces within the four regions (Eastern Indonesian, Java, Jakarta and Sumatera) below, disparity in regional inflation is observed. Generally, inflation rates in the Sumatera and Eastern Indonesian regions are relatively higher compared to other regions. ${ }^{6}$ A higher inflation rate in those two regions is mostly caused by the price volatility of a few food commodities that are imported from the Java region.

From the end of 2005 to end of 2006, the extent of inflation disparity between regions widened due to the inflation shock from the government's decision to increase fuel prices. The impact from fuel prices increase was larger in the Sumatera region compared to other regions. Inflation disparity remains a challenge in Indonesia, which requires policymakers to factor in the heterogeneities among regions and also the implication of their policies that would have an impact on regional inflation.

6 The Java region has fertile agricultural land and better access for distribution of food commodities. Most of the rice crops are still produced in this region. 


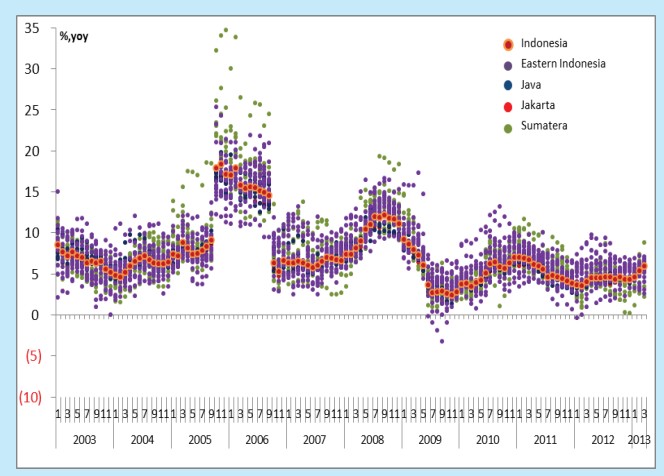

Figure 3.

Disparity of Regional Inflation, 2003 - 2012

\subsection{Impact of Fiscal Decentralization on Regional Inflation}

To examine the effects of fiscal decentralization and local government performance on regional inflation rate, a panel data analysis is constructed with data from 26 provinces from 2003 to 2008. The dependent variable is regional inflation rate $(\Pi)$ and the independent variables in the log expression are: the ratio of fiscal decentralization (FD) and the index of local government performance $(L G)$. The control variable is the regional population $(P)$, which is a proxy indicator for the size and scale of the regions. The following equation (1) is the expression of the relationship between regional inflation rate and variables of decentralization:

$$
\pi_{i t}=a+b \ln F D_{i t}+c \ln L G_{i t}+d \ln P_{i t}+u_{i t}
$$

The finding in Table 1 confirms that a higher degree or ratio of fiscal decentralization is correlated with a higher regional inflation rate, among others due to the extent of spending inefficiency. The result of the panel data regression implies that a one percentage point increase in the ratio of fiscal decentralization will increase the regional inflation rate by approximately 0.65 percentage point for the whole sample. The ratio of fiscal decentralization's coefficient has the expected positive sign and it is significant at 5 percent. On the other hand, the model does not imply a significant relationship between the local government performance and regional inflation rate, although variable local government performance has a negative sign on the coefficient as expected. 


\begin{tabular}{l|c|c|c}
\multicolumn{3}{c}{ Table 1 } \\
\hline Dependent Var: & Regional Inflation Rate & & \\
\hline \multicolumn{1}{c|}{ Independent Var. } & Coefficient & Std. Error & t-Statistic \\
\hline $\begin{array}{l}\text { Log Fiscal } \\
\text { Decentralization }\end{array}$ & 0.645 & 0.270 & $2.39^{*}$ \\
\hline $\begin{array}{l}\text { log Local Government } \\
\text { Performance }\end{array}$ & -0.393 & 0.292 & -1.35 \\
\hline $\begin{array}{l}\text { Log Population } \\
\text { Log-Likehood }\end{array}$ & -0.461 & 0.272 & -1.69 \\
\hline $\begin{array}{l}\text { R-squared } \\
\text { Note: * The point estimate is significant at the } 5 \%(0.05) \text { level. }\end{array}$ & & \\
\hline
\end{tabular}

\subsection{Convergence Analysis}

Before statistical examination using regression is performed to test Beta convergence, a scatter plot is generated to test the existence of convergence graphically. The scatter plot is shown between the logarithms of regional inflation in the base year (2003) on the x-axis, and the logarithms of the regional inflation over the period from 2003 to 2012 on the $y$-axis.

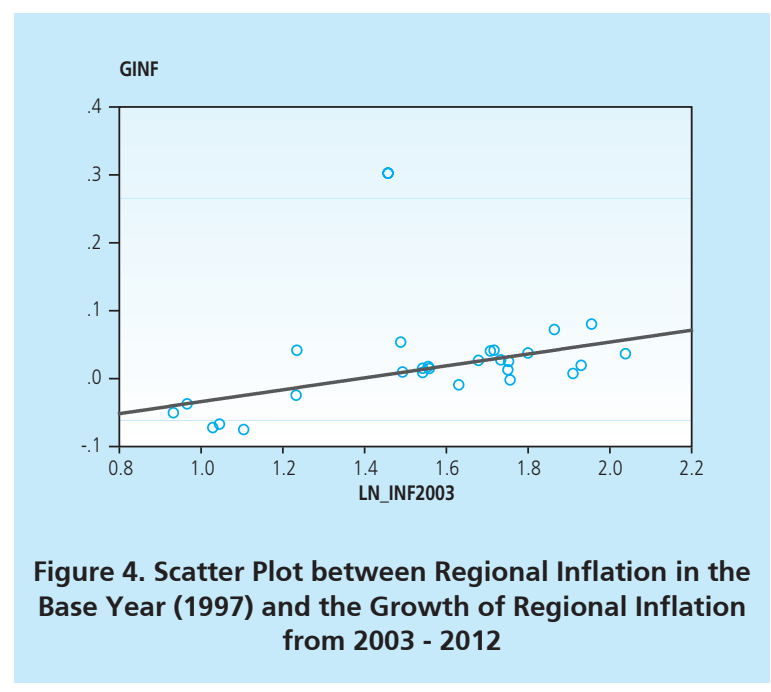

From the scatter plot, a positive sloped line can be observed, which means there is a positive relation between the regional inflation in the first observed year (the base year) and the growth of the regional inflation over the entire observed years. Thus, there is no indication of the presence of convergence. 
This result is supported by the Sigma $(\Sigma)$ convergence test that uses standard deviation of logarithms of GRDP per capita and measures the dispersion among standard deviations of regional inflation over period of years. The result indicates that regional inflation convergence did not take place during the period of observation from 2003 to 2012. If the year of observation is changed from 2008 to 2012, which coincides with the establishment of RITF, there is an indication of convergence although the process of convergence is slow. This finding is different from what was experienced by other countries and regions. ${ }^{7}$

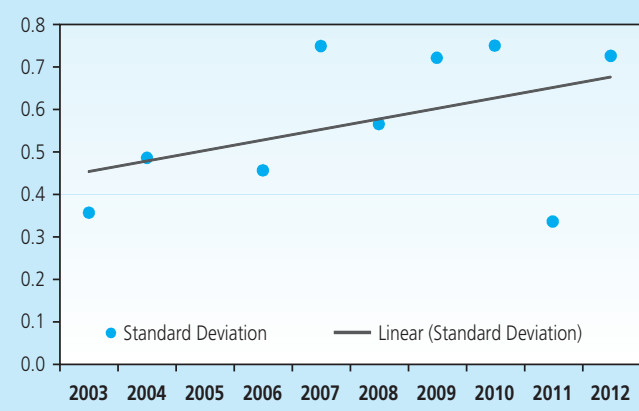

Figure 5.

Convergence of Regional Inflation, 2003-2013

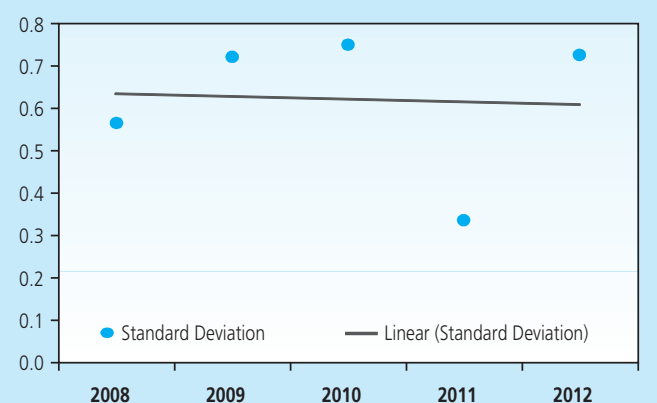

Figure 6.

Convergence of Regional Inflation, 2008-2012

The results of the Beta convergence test as shown in Table 2 indicates that the parameter of the convergence is positive and significant or there is no indication of convergence in regional inflation. When the same analysis is performed using 2008 as the initial year, which was the year when RITF established, the parameter of $\beta$ convergence is negative but not significant

Table 2

Unconditional $\beta$ Convergence of Inflation Rate, 2003 - 2012

\begin{tabular}{|c|c|c|c|}
\hline Dependent Var: & $\begin{array}{l}\text { Growth of Regional } \\
\text { Inflation Rate }\end{array}$ & & \\
\hline Independent Var. & Coefficient & Std. Error & t-Statistic \\
\hline B & 0,088 & 0,035 & $2,50^{*}$ \\
\hline Constant & $-0,122$ & 0,056 & $-2,17$ \\
\hline Log-Likehood & 42,10 & & \\
\hline R-squared & 0,18 & & \\
\hline
\end{tabular}

7 Similar to Indonesia, Turkey which has implemented inflation targeting since 2005, experienced a convergence in its regional inflation rates (year). One of the factors that has made a difference is the geography between these two regions. As an archipelago country, infrastructure for connectivity between regions in Indonesia is still an issue. 


\begin{tabular}{|c|c|c|c|}
\hline \multicolumn{4}{|c|}{$\begin{array}{c}\text { Table } 3 \\
\text { Unconditional } \beta \text { Convergence of Inflation Rate, } 2008 \text { - } 2012\end{array}$} \\
\hline Dependent Var: & $\begin{array}{l}\text { Growth of Regional } \\
\text { Inflation Rate }\end{array}$ & & \\
\hline Independent Var. & Coefficient & Std. Error & t-Statistic \\
\hline B & $-0,175$ & 0,134 & $-1,30$ \\
\hline Constant & 0,223 & 0,328 & 0,68 \\
\hline Log-Likehood & 22,39 & & \\
\hline R-squared & 0,06 & & \\
\hline
\end{tabular}

(Table 3). In other words, there is an indication that institutions (RITF) play a role in supporting the catching-up process of regional inflation convergence in Indonesia.

\subsection{Spatial Correlation Test}

We use spatial autocorrelation to see if inflation in certain region is influenced by the dynamics of inflation in neighboring regions. A poor infrastructure in several regions could affect distribution of goods for the surrounding regions. Another example is a drought that results in lower harvest in a region which could potentially affect the availability of food in surrounding regions, which could be exacerbated if imports are limited. Local government policies, such as taxes or fees on farm production and distribution, or protective policies on imports, could also impact inflation both in the respective region and also in surrounding regions.

The spatial autocorrelation model using Geoda application demonstrates a relatively high spatial autocorrelation of regional inflation in Indonesia. The Moran's Index is at +0.6 , which indicates a clustered condition of regional inflation. ${ }^{8}$ This finding may be driven by the geographic condition of Indonesia as an archipelago nation, where the structure of the economy is clustered within the Sumatera, Java (including the capital city Jakarta), Bali and Nusa Tenggara, Kalimantan, Sulawesi, Maluku and Papua. With this clustered geographic condition, a number of issues related to inflation arise, such as the prices disparity of a number of food commodities.

Several factors play a role in determining the prices of food commodities, which eventually affect inflation rate in specific regions. The structure of supply chain, domestic production, quality of infrastructure and local tax or fees associated with the distribution of commodities are among others factors that influence the disparity of food prices. A survey by Bank Indonesia on foods resiliency in 2012 found that differences in transportation costs (transaction costs), input costs, level of incomes and foods supplies (both from domestic production and import) is statistically

8 Although there is a strong correlation between inflation rates in different regions, the decomposed inflation rates are quite dispersed. 
significant in explaining the disparity of regional food prices. The distance to Java regions as the main distribution center does matter in determining the transaction costs. Moreover, the quality of infrastructures in Java and Sumatera regions is relatively better compared to the Eastern Indonesian region.

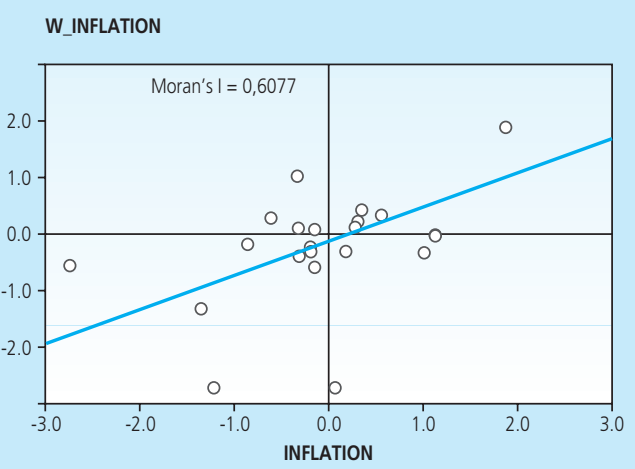

Figure 7.

Moran's Autocorrelation

\subsection{Impact of RITF on Regional inflation}

The last empirical test in this paper is to determine whether RITF has a negative correlation with the volatility of inflation. It is expected that the coordination and cooperation between regions in controlling inflation improved after the forming of RITF due to better awareness of local governments towards inflation problems in their respective regions. ${ }^{9}$

Panel Least Square regression with a 10-year observation data from 2003 - 2012 is used to measure the possible contribution of RITF on controlling inflation volatility in their respective regions. Inflation volatility as a measure of standard deviation of province's monthly inflation rate is considered a proper way to analyze the contribution of RITF in controlling inflation. Variable dummy RITF is accounted for a 4-year establishment of RITF, beginning in 2009. The sample observation includes four provinces (West Java, North Sumatera, South Sulawesi and East Nusa Tenggara) that were awarded for their accomplishment in controlling inflation in 2011 and

9 Multi departmental and sector coordination is the focus of RITF in controlling the volatility of regional inflation since a lot of issues in controlling regional inflation are caused by the lack of coordination and collaboration within the internal departmental of local governments. Although RITF is commonly engaged in the formulation of policy to control inflation, there are some cases where RTIF are directly involved in supporting programs that aim to control inflation. Such program would be the development of regional information center for market prices, particularly for food commodities. In term of coordination between RITF and central government agencies, a national coordination meeting is held annually. In addition, a national coordinating committee (National Inflation Task Force or NITF) is also established to strengthen the communication, coordination and collaboration between RITF and central government. Bank Indonesia has actively participated in both the NITF and RITF as part of an effort to meet the inflation target. 
2012. As the control variables, we use dummy fuel adjustment shock and percentage growth in weighted global commodity prices, with the largest impact on Indonesia's economy. High inflation in Indonesia, driven by a price increase in subsidized fuels by government, occurred in 2005 and 2008.

\begin{tabular}{|c|c|c|c|}
\hline \multicolumn{4}{|c|}{$\begin{array}{c}\text { Table } 4 \\
\text { Panel Least Square of Regional Inflation, 2003-2012 }\end{array}$} \\
\hline Dependent Var: & Regional Inflation Rate & & \\
\hline Independent Var. & Coefficient & Std. Error & t-Statistic \\
\hline $\mathrm{C}$ & 5.341 & 0,611 & $8,74^{*}$ \\
\hline Dummy_RITF & $-1,062$ & 0,912 & $-1,16$ \\
\hline Dummy Fuel Shock & 7,319 & 1,235 & $5,92^{*}$ \\
\hline Global Commodity Prices & 0,051 & 0,022 & $2,24^{* *}$ \\
\hline
\end{tabular}

The result shows a negative correlation between RITF dummy and the dependent variable of inflation volatility. The relationship between those two variables is not significant and there fore, the coefficient cannot be interpreted. This finding is consistent with previous analysis that shows in significant correlation between local government and regional inflation. The fact that the contribution of RITF in controlling the inflation cannot be fully determined indicates that other factors play a role. Along with that line of thought is the extent of shock from tradable inflation. There is a limitation of what RITF can do to control inflation when there is a price shock in tradable goods and services, due to the dynamic of global commodity supply and demand. Based on this model, positive shock on fuel prices and the rising global commodity prices have a positive correlation with inflation volatility.

\section{CONCLUSION}

This paper internalize institutional variable in determining the dynamics of regional inflation during the era of decentralization in Indonesia. This paper finds that decentralization does have an impact on regional inflation in Indonesia, where an increase in the degree of fiscal decentralization also increases the volatility of regional inflation. Among others, this is due to inefficiency in local government expenditures. Although the variable of local government performance is not significant, the negative correlation between local government performance and regional inflation rate is evident as expected. Thus, to some extent, institutions do play a role in controlling inflation in the regions. In addition, there is also an indication that institutions have a role in reducing the disparity of regional inflation in Indonesia, although convergence in regional inflation rate is not observed in this study. 
From a spatial perspective, there is evidence of high spatial autocorrelation of regional inflation in Indonesia. There is also a strong indication of the lack of coordination between regions (local governments) in controlling regional inflation before the forming of RITF. On this study, the contribution of RITF in controlling inflation volatility cannot be determined, even though the nature of their correlation is negative, as expected. Since the problem of inflation in Indonesian is partly related to supply side, then the coordination and cooperation within institutions both in local and central level is crucial. In the future, RITF should prioritize the formulation of long term policy to control inflation since it would resolve the major or structural problems and provide a more stable inflationary environment. 


\section{REFERENCES}

Alesina, Alberto and Allan Drazen, 1991. "Why Are Stabilizations Delayed?" , American Economic Review, 81: 1170-1188

Ball L and N Sheridan (2004), 'Does inflation targeting matter?', in BS Bernanke and M Woodford (eds), Inflation Targeting, University of Chicago Press, Chicago

Bardhan, P. (2002), 'Decentralization of Governance and Development', Journal of Economic Perspectives, 16 (4): 185-205.

Barro, R.J. \& D.B. Gordon (1983), 'Rules, Discretion and Reputation in A Model of Monetary Policy', Journal of Monetary Economics, 12(1): 101-121.

Beck, G.W. and Weber, A.A., (2001), 'How Wide are European Borders? New Evidence on the Integration Effects of Monetary Unions', CFS Working Paper No: 2001/07

Brodjonegoro, B., (2004), 'The Indonesian Decentralization After Law Revision: Toward A Better Future?', Paper was presented at the International Symposium on Fiscal Decentralization in Asia Revisited, Tokyo, Japan.

Busetti F., L. Forni, A. Harvey and F. Venditti, 2007, Inflation Convergence and Divergence within the European Monetary Union, Working Paper No. 574, European Central Bank, January 2006

Campbell, et al. (1991), "Decentralization to Local Government in LAC: National Strategies and Local Repsonse in Planning, Spending, and Management," Report No.5, Latin America and The Caribbean Technical Department, Regional Studies Program, World Bank, Washington.

Cliff, A.D. and J.K. Ord (1973), Spatial Autocorrelation, Pion.

European Central Bank (2003), 'Inflation Differentials in The Euro Area: Potential Causes and Policy Implications', Frankfurt am Main.

Feltenstein, A. and S. Iwata (2002), 'Decentralization and Macroeconomic Performance in China: Regional Autonomy Has its Costs', Manuscript, IMF.

Herrera, S. and G. Pang (2005), 'Efficiency of Public Spending in Developing Countries: An Efficiency Frontier Approach', Working Paper Series No. 3645, World Bank. 
Holmes (2002), 'Panel data evidence on inflation convergence in the European Union', Applied Economic Letters, Vol. 9

Honohan and Lane (2003), 'Inflation Divergence', Economic Policy, October Edition.

Hossain, A.A. (1996), Monetary and Financial Policies in Developing Countries: Growth and Stabilization, Routledge.

King, D. and Y. Ma (2001), "Fiscal Decentralization, Central Bank Independence and Inflation", Economic Letters 72, 95-98.

Mohanty, M.S. and M. Klau (2001). 'Fiscal Decentralization in Developing Countries: Is It Happening? How Do We Know?', Bank for International Settlements Paper No. 8.

Neyapti, B. (2003), 'Herrera, S. and G. Pang (2005), 'Efficiency of Public Spending in Developing Countries: An Efficiency Frontier Approach', Working Paper Archive of the Department of Economics, Bilkent University.

Tirtosuharto, D. (2010), The Impact of Fiscal Decentralization and State Allocative Efficiency on Regional Growth in Indonesia', Journal of International Commerce, Economics and Policy, 1 (2): 287-307.

Treisman, D. (2000), 'Decentralization and Inflation: Commitment, Collective Action, or Continuity', The American Political Science Review, 94(4): 837-857.

Vazquez, J.M. and R.M. McNab (2006), 'Fiscal Decentralization, Macrostability, and Growth', Revista de Economía Pública, 179(4): 25-49.

Wimanda, R.E. (2006), 'Regional Inflation in Indonesia: Characteristic, Convergence, and Determinants', Working Paper No. 13, Bank Indonesia.

Zsibók, Z. and B. Varga (2009). 'Inflation Persistence in Hungary: a Spatial Analysis', Department of Mathematical Economics and Economic Analysis, Corvinus Univ. of Budapest Working Paper No. 1203. 